\title{
Effects of written action plan adherence on COPD exacerbation recovery
}

\author{
Erik W M A Bischoff, ${ }^{1,2}$ Dina H Hamd, ${ }^{2}$ Maria Sedeno, ${ }^{2}$ Andrea Benedettii, ${ }^{2,3,4}$ \\ Tjard R J Schermer, ${ }^{1}$ Sarah Bernard, ${ }^{5}$ François Maltais, ${ }^{5}$ Jean Bourbeau ${ }^{2,3,4}$
}

1Department of Primary and Community Care, Radboud University Nijmegen Medical Centre, Nijmegen, The Netherlands

${ }^{2}$ Respiratory Epidemiology and Clinical Research Unit, Montreal Chest Institute, McGill University Health Centre, Montréal, Canada

${ }^{3}$ Department of Epidemiology, Biostatistics and Occupationa Health, McGill University, Montréal, Canada

${ }^{4}$ Centre de recherche de I'Institut Universitaire de Cardiologie et de Pneumologie de l'Université Laval, Québec, Canada

${ }^{5}$ Department of Medicine, McGill University, Montréal, Canada

\section{Correspondence to} Jean Bourbeau, Respiratory Epidemiology and Clinical Research Unit, Montreal Chest Institute, 3650 St Urbain, Montréal H2X 2P4, Canada; jean.bourbeau@mcgill.ca

Received 18 September 2009 Accepted 2 September 2010 Published Online First 30 October 2010

\begin{abstract}
Background The effects of written action plans on recovery from exacerbations of chronic obstructive pulmonary disease (COPD) have not been well studied. The aims of this study were to assess the effects of adherence to a written action plan on exacerbation recovery time and unscheduled healthcare utilisation and to explore factors associated with action plan adherence.
\end{abstract}

Methods This was a 1-year prospective cohort study embedded in a randomised controlled trial. Exacerbation data were recorded for 252 patients with COPD who received a written action plan for prompt treatment of exacerbations with the instructions to initiate standing prescriptions for both antibiotics and prednisone within 3 days of exacerbation onset. Following the instructions was defined as adherence to the action plan.

Results From the 288 exacerbations reported by 143 patients, start dates of antibiotics or prednisone were provided in 217 exacerbations reported by 119 patients (53.8\% male, mean age 65.4 years, post-bronchodilator forced expiratory volume in $1 \mathrm{~s}\left(\mathrm{FEV}_{1}\right) 43.9 \%$ predicted) In $40.1 \%$ of exacerbations, patients adhered to their written action plan. Adherence reduced exacerbation recovery time with statistical $(p=0.0001)$ and clinical ( -5.8 days) significance, but did not affect unscheduled healthcare utilisation (OR $0.94,95 \% \mathrm{Cl} 0.49$ to 1.83). Factors associated with an increased likelihood of adherence were influenza vaccination, cardiac comorbidity, younger age and lower $\mathrm{FEV}_{1}$ as percentage predicted.

Conclusions This study shows that adherence to a written action plan is associated with a reduction in exacerbation recovery time by prompt treatment. Knowing the factors that are associated with proper and prompt utilisation of an action plan permits healthcare professionals to better focus their self-management support on appropriate patients.

\section{INTRODUCTION}

The increasing burden of chronic obstructive pulmonary disease (COPD) on healthcare systems worldwide is mainly caused by exacerbations. ${ }^{1}$ These acute events of sustained worsening of the respiratory condition are common in COPD. ${ }^{2}$ Exacerbations have a considerable effect on patients' health status ${ }^{34}$ and contribute to COPDrelated costs. ${ }^{5}$ Recovery from exacerbations varies from 7 to 14 days, $^{2}$ and it may take even longer to return to activities of daily living. ${ }^{4}$ Despite the huge impact exacerbations may have, patients often have problems in recognising symptom deterioration ${ }^{6}$ and fail to report exacerbations. ${ }^{2} 7$ This causes a delay in treatment which has been associated with an increased symptom recovery time, ${ }^{2}$ a worsening of health status ${ }^{4}$ and an increased risk of hospitalisation. ${ }^{8}$ Leading respiratory societies emphasise enhancement of patients' awareness of exacerbation symptoms and the importance of early intervention. ${ }^{59}$

Self-management education strategies have been shown to improve exacerbation outcomes-for example, by reducing hospital admissions. ${ }^{10} 11$ Effective self-management programmes include written action plans which enable patients with COPD to recognise symptom deterioration in the event of an exacerbation and to react appropriately by prompt initiation of prednisone and/or antibiotics. $^{12}$ In the complex sequence of effects resulting from a self-management intervention, it is important to assess patient-reported outcomes if we want to reduce the burden of COPD exacerbations and to claim the benefit of this intervention. The PERCEIVE study has shown that $45 \%$ of patients had to stay in bed or on a couch all day during exacerbations; most importantly, 55\% declared that quicker symptom relief was the most desired requirement for treatment. ${ }^{14}$ Although the use of action plans has been proposed for early recognition and prompt access to treatment, ${ }^{15}$ there is currently no evidence that this strategy will improve patient-reported outcomes such as symptom recovery. ${ }^{16}$

In the present study the primary aim was to assess the effects of adherence to a written action plan for prompt treatment of exacerbations with standing prescriptions for antibiotics and prednisone on exacerbation recovery time and unscheduled healthcare utilisation. As a secondary objective, patient and disease characteristics that are associated with an enhancement of written action plan adherence were explored.

\section{METHODS}

\section{Study design}

This study was designed as a prospective cohort study embedded within a 1-year randomised clinical trial ${ }^{17} 18$ (http://ClinicalTrials.gov identifier: NCT00169897) which compared the effectiveness of outpatient hospital-based exercise training versus self-monitored home-based exercise training. The methodology of the randomised clinical trial has been described in detail elsewhere. ${ }^{17} 18$ Before randomisation to 8 weeks of either hospital- or home-based exercise training, patients received 4 weeks of group education with the self-management programme 'Living Well with COPD'. This 
programme is available at http://www.livingwellwithcopd.com (password: copd). ${ }^{19-21}$ The programme included the use of a written action plan that focused on prompt treatment of COPD exacerbations with standing prescriptions for antibiotics and oral prednisone. All patients were instructed to initiate both prednisone and antibiotics within 3 days of a change for at least $24 \mathrm{~h}$ in at least two of the following three major symptoms: dyspnoea, sputum volume and sputum colour. In each exercise training group, patients were followed by a trained respiratory nurse or respiratory therapist acting as a case manager. The case manager contacted patients every 2 months to reinforce mastery of the intended behaviour and was available for given advice during business hours.

\section{Study subjects}

Between 1 January 2004 and 31 November 2005, 10 Canadian centres recruited 252 patients who fulfilled the following inclusion criteria: age $\geq 40$ years; forced expiratory volume in $1 \mathrm{~s}$ $\left(\mathrm{FEV}_{1}\right)$ post-bronchodilator $<70 \%$ predicted and ratio of $\mathrm{FEV}_{1}$ to forced vital capacity (FVC) $<0.70$; smoking history $\geq 10$ pack years; and MRC dyspnoea scale $\geq 2$.

\section{Measurements}

Patients recorded their symptoms, medications and use of healthcare services in a diary. Through standardised monthly telephone interviews, independent research assistants evaluated the diaries for the presence of respiratory symptom changes in the previous month. If so, the interviewer recorded in detail the start and end dates of symptom change; start and end dates of prednisone and antibiotics used, if any; contact with the case manager; unscheduled doctor and emergency room visits and hospital admissions. Spirometry was measured at baseline and at 3 and 12 months. The study definition of adherence to the action plan was based on the instructions given to all enrolled patients - that is, the initiation of both prednisone and antibiotics within 3 days of a change for at least $24 \mathrm{~h}$ in at least two of the following three major symptoms: dyspnoea, sputum volume and sputum colour. All other actions were considered as nonadherence. We also used an additional definition-namely, the initiation of prednisone and/or antibiotics within 3 days of a change for at least $24 \mathrm{~h}$ in at least two of the three major symptoms.

Exacerbations were defined as a change for at least $24 \mathrm{~h}$ in at least two of the three major symptoms (dyspnoea, sputum volume and sputum colour). ${ }^{22}$ Exacerbations were only considered as new events if there was a time difference of at least 14 days between the exacerbation start date and the end date of the previous one. Exacerbation total recovery time was calculated as the time between exacerbation start date (date of reported symptom change) and end date (when symptoms had returned to baseline level). Treated recovery time was calculated as the time between the medication start date and the exacerbation end date. ${ }^{8}$ Treatment delay was calculated as the time between the exacerbation start date and the medication start date. Unscheduled healthcare utilisation was defined as the use of one ore more of the following medical services as recorded in the diaries: unscheduled doctor visit, emergency room visit and hospital admission due to COPD exacerbations.

\section{Statistical analysis}

Crude associations between the dependent variables exacerbation total recovery time and unscheduled healthcare utilisation and the independent dichotomous variable adherence to the action plan were calculated using simple linear and logistic regression analyses. These associations were then adjusted for the covariates age, sex, post-bronchodilator $\mathrm{FEV}_{1} \%$ predicted, smoking status, exacerbation severity, contacting the case manager, cardiac disease, use of long-acting bronchodilators and inhaled corticosteroids, influenza vaccination, exacerbation sequence during follow-up and randomisation group in the randomised controlled trial. Before entering the models, correlations between variables were tested and highly correlated variables were dropped. Because of the hierarchical structure of our dataset, intraclass correlation coefficients (ICC) adjusted for the covariates were calculated to explore the clustering effect of exacerbations within subjects and subjects within study centres. Although the ICC of both subject $(<0.0001)$ and study centre (0.017) was low, we used generalised mixed models with exacerbation occurrence as the unit of analysis and subject and study centre as random effects. For the outcome exacerbation total recovery time, we estimated linear mixed models via restricted maximum likelihood (REML) and, for the outcome unscheduled healthcare utilisation, we estimated logistic mixed models via residual pseudo-likelihood (RSPL). Using comparable analyses we also studied the additional definition of action plan adherence and conducted a worst case analysis in which the exacerbations with missing start dates of antibiotics or prednisone $(n=71)$ were included by considering their treatment as failure to adherence.

To explore the relationship between patient and exacerbation characteristics and adherence to the action plan, we estimated logistic mixed models via RSPL with action plan adherence as outcome and subject and study centre as random effects. Inclusion of variables was based on hypothesis as previous research on this topic was not available. We first performed univariable analyses to explore individual associations between action plan adherence and the factors age, sex, post bronchodilator $\mathrm{FEV}_{1} \%$ predicted, exacerbation severity, number of emergency room visits for COPD in the 12 months prior to the study, having an exacerbation action plan prior to the study, contacting the case manager, cardiac disease, depressive symptoms, influenza vaccination, exacerbation sequence during follow-up and randomisation group in the randomised controlled trial. Multivariable analyses were then conducted to explore the effects of all variables together on the dependent variable adherence to the action plan. Backward elimination was used to remove variables with $\mathrm{p}>0.05$.

The statistical package SPSS Version 16.0.2 was used to calculate baseline characteristics and correlation coefficients and for performing simple linear and logistic analyses. All generalised mixed models were performed using SAS Version 9.2. We considered $p$ values $<0.05$ as statistically significant.

\section{RESULTS}

\section{Patient and exacerbation characteristics}

A total of 143 patients $(56.7 \%$ of the 252 participants in the randomised controlled trial) reported 288 events that met the study definition of exacerbation. Seventy-one (24.7\%) of the 288 exacerbations were excluded due to missing start dates of antibiotics or prednisone. Excluded and included exacerbations were similar with regard to exacerbation recovery time $(p=0.470)$, respiratory symptoms $(p=0.160)$ and patients' age $(p=0.978)$, sex $(p=0.496)$ and $\mathrm{FEV}_{1}(p=0.141)$. The remaining 217 exacerbations were reported by 119 patients. Table 1 shows the baseline characteristics of these 119 patients who were included in the subsequent analyses. Overall, slightly more than half of the patients were male and most of them had moderate to severe airflow obstruction. The majority were prescribed a combination 
Table 1 Subject characteristics at baseline $(n=119)$

\begin{tabular}{|c|c|}
\hline Characteristic description & Data at baseline \\
\hline Age, years & $65.4(9.2)$ \\
\hline Male & $64(53.8)$ \\
\hline Years of education & $11.2(4.0)$ \\
\hline Current smoker & $23(19.3)$ \\
\hline Pack years & $58.8(39.0-67.5)$ \\
\hline $\mathrm{BMI}, \mathrm{kg} / \mathrm{m}^{2}$ & $27.2(5.9)$ \\
\hline Post-BD FEV $1, I$ & $1.07(0.32)$ \\
\hline Post-BD FEV $1, \%$ predicted & $43.9(13.3)$ \\
\hline Post-BD FEV $1 / F V C$ & $0.43(0.11)$ \\
\hline 6-min walking distance, $\mathrm{m}$ & $339(284-395)$ \\
\hline \multicolumn{2}{|l|}{ Dyspnoea score (MRC) } \\
\hline $2 / 5$ & $29(24.6)$ \\
\hline $3 / 5$ & $53(44.9)$ \\
\hline $4 / 5$ & $25(21.2)$ \\
\hline $5 / 5$ & $11(9.3)$ \\
\hline ER visits for COPD in previous 12 months & $0.65(1.05)$ \\
\hline ICS and LABD & $91(76.5)$ \\
\hline \multicolumn{2}{|l|}{ Comorbidity } \\
\hline Depressive symptoms* & $32(29.9)$ \\
\hline Cardiac disease $\dagger$ & $29(24.4)$ \\
\hline $\begin{array}{l}\text { Exacerbation intervention plan prior to } \\
\text { study }\end{array}$ & $48(41.0)$ \\
\hline Influenza vaccination & $95(80.5)$ \\
\hline \multicolumn{2}{|l|}{ Intervention group in $\mathrm{RCT} \ddagger$} \\
\hline Home-based rehabilitation & $60(50.4)$ \\
\hline Hospital-based rehabilitation & $59(49.6)$ \\
\hline \multicolumn{2}{|c|}{$\begin{array}{l}\text { Data are expressed as mean (SD) or median (IQR) for continuous } \\
\text { variables or number (\%) for categorical variables. } \\
\text { *Depressive symptoms were measured with the } 15 \text {-item Geriatric } \\
\text { Depression Scale (GDS). Numbers presented include scores suggestive } \\
\text { for depression (score } \geq 6 \text { points). } \\
\text { †Cardiac disease includes chronic heart failure, angina pectoris, } \\
\text { myocardial infarction and arrhythmia. } \\
\text { †Canadian pulmonary rehabilitation trial (http://ClinicalTrials.gov } \\
\text { identifier: NCTO0169897). } \\
\text { AP, action plan; BD, bronchodilator; BMl, body mass index; ER, } \\
\text { emergency room; FEV } \text {, forced expiratory volume in } 1 \mathrm{~s} \text {; FVC, forced vita } \\
\text { capacity; ICS, inhaled corticosteroid; LABD, long-acting bronchodilator; } \\
\text { MRC, Medical Research Council. }\end{array}$} \\
\hline
\end{tabular}

of long-acting bronchodilators and inhaled corticosteroids. Less than half had been prescribed an intervention plan for COPD exacerbations prior to the study, but this was usually provided as verbal instruction and patients were usually not followed by a case manager.

Table 2 shows the characteristics of the 217 exacerbations analysed. The mean (SD) number of exacerbations per patient was 1.8 (1.2). Slightly more than half of the patients reported only one exacerbation. In most exacerbations there was a worsening of all three major symptoms whereas, in $<10 \%$ of the exacerbations, patients reported a combination of sputum increase with sputum colour change without dypsnoea change. The overall mean (SD) exacerbation total recovery time was 14.0 (9.4) days (median 10.0 days (IOR 8.0-17.0)). Five exacerbations had missing data on the use of unscheduled healthcare services. Half of the exacerbations required unscheduled healthcare utilisation of which most required only unscheduled doctor visits. Less than $10 \%$ of the exacerbations required emergency room visits followed by hospital admission.

\section{Action plan adherence, exacerbation recovery time and unscheduled healthcare utilisation}

Overall, the median treatment delay was 1.0 day (IOR 0.0-3.5). In 141 exacerbations (65.0\%) patients initiated both antibiotics
Table 2 Exacerbation characteristics $(n=217)$

\begin{tabular}{|c|c|}
\hline Characteristic description & Results \\
\hline Exacerbation frequency (per patient per year) & $1.8(1.2)$ \\
\hline \multicolumn{2}{|l|}{ Patients with } \\
\hline 1 exacerbation & $67(56.3)$ \\
\hline 2 exacerbations & $24(20.2)$ \\
\hline 3 exacerbations & $17(14.3)$ \\
\hline 4 or more exacerbations & $11(9.2)$ \\
\hline \multicolumn{2}{|l|}{ Exacerbation symptoms } \\
\hline $\begin{array}{l}\text { Increase in dyspnoea and sputum, change } \\
\text { in sputum colour }\end{array}$ & $136(32.7)$ \\
\hline Increase in dyspnoea and sputum & $30(13.8)$ \\
\hline $\begin{array}{l}\text { Increase in sputum and change in sputum } \\
\text { colour }\end{array}$ & $19(8.8)$ \\
\hline $\begin{array}{l}\text { Increase in dyspnoea and change in sputum } \\
\text { colour }\end{array}$ & $32(14.7)$ \\
\hline Exacerbation total recovery time, days & $14.0(9.4)$ \\
\hline Treated recovery time, days & $11.6(7.9)$ \\
\hline \multicolumn{2}{|c|}{ Exacerbations with unscheduled healthcare utilisation* } \\
\hline Total & $107(50.5)$ \\
\hline Unscheduled doctor visit & $70(33.0)$ \\
\hline ER & $20(9.4)$ \\
\hline $\mathrm{ER}+$ hospital admission & $17(8.0)$ \\
\hline
\end{tabular}

and prednisone, whereas in only 8 exacerbations (3.7\%) patients failed to start any oral medication. Patients were adherent to their action plan in 87 (40.1\%) of the reported exacerbations. Exacerbations in which patients were non-adherent consisted of events treated with only prednisone $(n=11,8.5 \%)$, only antibiotics ( $\mathrm{n}=61,46.9 \%$ ), both but not within the 3-day time delay $(n=50,38.5 \%)$ and those not treated with any oral medication $(n=8,6.2 \%)$. Using the additional definition of action plan adherence (initiation of prednisone and/or antibiotics within 3 days time delay) resulted in 133 exacerbations (61.3\%) in which patients were adherent. Of these exacerbations, 34 were treated with only antibiotics, 5 with only prednisone and 94 with both.

Table 3 shows that exacerbations in which patients were adherent had a faster recovery ( -5.08 days) to baseline than exacerbations in which patients were non-adherent $(p=0.0001)$. The effect on exacerbation total recovery time remained significant when analysing only patients' first and last exacerbations (-7.09 days, $95 \%$ CI -3.63 to $-10.56, \quad p=0.0001$ and -4.99 days, $95 \%$ CI -0.95 to $-9.03, p=0.016$, respectively; data not shown). When analysing the additional definition of action plan adherence (initiation of prednisone and/or antibiotics within 3 days time delay), the effect on total recovery time increased; the increase was both clinically and statistically significant (7.43 days, $\quad p=0.0001)$. Furthermore, when conducting the worst case analysis, the effect remained significant. The difference in treated recovery time between action plan adherence and non-adherence was not statistically significant. There was no difference observed in the use of unscheduled healthcare services between exacerbations in which patients were adherent and non-adherent using the study definition and the additional definition of adherence and when conducting the worst case analysis.

After adjustment for potential confounding factors, the association between adherence to the action plan and exacerbation total recovery time increased to -5.84 days $(95 \% \mathrm{CI}$ 
Table 3 Effect of adherence to the written action plan on exacerbation recovery time and unscheduled healthcare utilisation

\begin{tabular}{|c|c|c|c|c|c|c|c|c|}
\hline \multirow{2}{*}{$\begin{array}{l}\text { Study definition* ( } n=217 \\
\text { exacerbations) }\end{array}$} & \multicolumn{2}{|l|}{ Adherence } & \multicolumn{3}{|l|}{ Crude } & \multicolumn{3}{|c|}{ Adjusted } \\
\hline & Yes $(n=87)$ & No $(n=130)$ & $\mathrm{B} / \mathbf{O R}$ & $95 \% \mathrm{CI}$ & p Value & B/OR & $95 \% \mathrm{Cl}$ & p Valu \\
\hline Exacerbation total recovery time, days & $10.9(5.6)$ & $16.0(10.7)$ & -5.08 & -7.62 to -2.55 & 0.0001 & -5.84 & -8.44 to -3.23 & 0.0001 \\
\hline Treated recovery time, days & $10.5(5.6)$ & $12.3(9.0)$ & -1.8 & -4.03 to 0.42 & 0.112 & -2.21 & -4.58 to 0.16 & 0.072 \\
\hline Unscheduled healthcare utilisation, yes§ & $42(49.4)$ & $65(51.2)$ & 0.93 & 0.54 to 1.61 & 0.801 & 0.94 & 0.49 to 1.83 & 0.864 \\
\hline $\begin{array}{l}\text { Additional definition } \dagger \text { ( } n=217 \\
\text { exacerbations) }\end{array}$ & Yes $(n=87)$ & No $(n=130)$ & & & & & & \\
\hline Exacerbation total recovery time, days & $11.2(6.8)$ & $18.6(11.1)$ & -7.43 & -9.91 to -4.96 & 0.0001 & -7.36 & -9.85 to -4.87 & 0.0001 \\
\hline Treated recovery time, days & $10.7(6.7)$ & $13.1(9.3)$ & -2.38 & -4.66 to 0.1 & 0.040 & -2.04 & -4.37 to 0.29 & 0.090 \\
\hline Unscheduled healthcare utilisation, yes§ & $39(50.6)$ & $65(50.0)$ & 0.97 & 0.67 to 1.72 & 0.928 & 0.99 & 0.52 to 1.96 & 0.978 \\
\hline $\begin{array}{l}\text { Worst case analysis } \neq \text { ( } n=288 \\
\text { exacerbations) }\end{array}$ & Yes $(n=87)$ & No $(n=201)$ & & & & & & \\
\hline Exacerbation total recovery time, days & $10.9(5.6)$ & $15.0(10.2)$ & -4.09 & -6.46 to -1.72 & 0.001 & -4.87 & -7.31 to -2.43 & 0.0002 \\
\hline Unscheduled healthcare utilisation, yes§ & $42(49.4)$ & $109(55.1)$ & 0.8 & 0.48 to 1.33 & 0.384 & 0.78 & 0.43 to 1.41 & 0.412 \\
\hline
\end{tabular}

${ }^{*}$ Action plan adherence was defined as the initiation of both prednisone and antibiotics within 3 days of exacerbation onset. All other actions were defined as non-adherence.

tIn the additional definition, adherence was defined as the initiation of prednisone and/or antibiotics within 3 days of exacerbation onset. All other actions were defined as non-adherence. ¥In the worst case analysis, all reported exacerbations were included considering the exacerbations with missing data on the use of antibiotics and/or prednisone as failure to adherence. Adherence was defined as the initiation of prednisone and antibiotics within 3 days of exacerbation onset. Treated recovery time was not calculated as the exacerbations that were added had missing start dates of treatment.

§Five exacerbations were excluded due to missing data concerning the use of unscheduled healthcare services.

ๆAdjusted for age, sex, post-bronchodilator forced expiratory volume in $1 \mathrm{~s}$ as percentage predicted, smoking status, exacerbation severity, contacting the case manager, cardiac disease, use of long-acting bronchodilators and inhaled corticosteroids, influenza vaccination, exacerbation sequence during follow-up and randomisation group in the randomised controlled trial.

$B$, regression coefficient (ie, change in recovery time with adherence).

-8.44 to 3.23$)$. Also, for the additional definition and in the worst case analysis, the association remained clinically and statistically significant. After adjustment, the differences in treated recovery time between adherence and non-adherence remained not statistically significant. Adjustment did not change the association between adherence and unscheduled healthcare utilisation.

\section{Adherence to the action plan and associated factors}

Table 4 shows the relationship between patient and disease characteristics and adherence to the action plan in the multilevel univariable and multivariable analyses. In the univariable analysis, adherence was more likely in exacerbations of patients with cardiac disease and those who received influenza vaccination. Patients with higher $\mathrm{FEV}_{1}$ were less likely to adhere to their written action plan. When combining all factors in the multivariable analysis, patients receiving influenza vaccination, having cardiac comorbidity, having more severe airflow obstruction and being younger had an increased likelihood of adhering to the action plan. After adjustment for the covariates, exacerbations within patients were slightly more similar to each other than to exacerbations in other patients $(\mathrm{ICC}=0.125)$ in terms of action plan adherence. Also, patients within a centre were slightly more similar to each other than to patients in other centres $(\mathrm{ICC}=0.134)$ in terms of action plan adherence.

\section{DISCUSSION \\ Main findings}

This study shows that adherence to a written action plan with instructions for prompt and proper treatment of exacerbations is associated with a statistically $(\mathrm{p}=0.0001)$ and clinically ( -5 days) significant reduction in exacerbation total recovery time. The study could not demonstrate a reduction in unscheduled healthcare utilisation. Factors such as receiving influenza vaccination, having a cardiac comorbidity, having more severe airflow obstruction and being younger increased the likelihood of adherence to the action plan.

This is the first study to demonstrate a positive association between the use of a written action plan and exacerbation total recovery time. This is important in view of new data showing that exacerbations are so disabling that patients have expressed that quicker symptom relief was the most desired treatment goal. ${ }^{14}$ Wilkinson and colleagues showed that a time delay in exacerbation treatment significantly extended exacerbation recovery time, with 0.42 days per additional day delay. ${ }^{8}$ They instructed patients to report exacerbations to the study team or the healthcare provider. The reported median delay in treatment was 3.7 days (IOR 2.0-5.6). Standing prescriptions as part of an action plan benefits early treatment as patients in the current study initiated medication with a median treatment delay of only 1.0 day (IOR $0.0-3.5$ ). Action plan adherence was also associated with a decrease of 2.2 days in treated recovery time, although this finding did not reach statistical significance. Our study was not sufficiently powered to show such a small difference. Action plan adherence was not associated with a reduction in the use of healthcare services. This is in contrast with recent studies on the use of COPD action plans. Sedeno and colleagues showed an association between the same written action plan and a reduction in hospital admission and emergency room visits, but included older subjects with a worse disability (6 min walking test and MRC dyspnoea score). ${ }^{23}$ In addition, Sridhar et al showed that a written action plan embedded in a care package containing pulmonary rehabilitation and selfmanagement education reduced the need for primary care consultations compared with care as usual after a 2-year follow-up. ${ }^{24}$

To improve the use of written action plans in daily practice, it is important to understand why patients may fail to adhere to their written action plan. In the present study, despite the training programme at the start and the support by case managers during the 1-year follow-up, in only $40.1 \%$ of the exacerbations did patients adhere to the action plan. However, the primary goal of the overall self-management intervention was exercise maintenance after completing a pulmonary rehabilitation programme. The intervention could have been more effective if it focused on the use of an action plan in the event of an exacerbation. Patients with worse disease severity (ie, lower lung function or cardiac comorbidity) were more likely to adhere to their action plan. This suggests a tendency among healthier patients to delay their treatment regardless of exacerbation 
Table 4 Factors associated with adherence to the action plan:* univariable and multivariable analyses on 217 exacerbations

\begin{tabular}{|c|c|c|c|}
\hline & Categories or units & $\mathbf{O R}$ & $95 \% \mathrm{Cl}$ \\
\hline \multicolumn{4}{|l|}{ Univariable analysis } \\
\hline Influenza vaccination & Yes vs no & 4.83 & 1.74 to 13.37 \\
\hline Cardiac disease $†$ & Yes vs no & 2.44 & 1.08 to 5.52 \\
\hline $\begin{array}{l}\text { Exacerbation intervention plan prior to } \\
\text { study }\end{array}$ & Yes vs no & 1.63 & 0.75 to 3.54 \\
\hline Post-BD FEV 1 & Each \% predicted & 0.98 & 0.96 to 1.00 \\
\hline Age & Each year & 0.98 & 0.94 to 1.02 \\
\hline Sex & Female vs male & 1.28 & 0.65 to 2.52 \\
\hline Exacerbation sequence & Each exacerbation & 1.11 & 0.84 to 1.46 \\
\hline Number of exacerbation symptoms & 3 vs 2 symptoms & 1.45 & 0.73 to 2.87 \\
\hline ER COPD visit prior to study & Each visit & 1.11 & 0.85 to 1.44 \\
\hline Contacting the case manager & Yes vs no & 1.19 & 0.6 to 2.38 \\
\hline Depressive symptoms $\ddagger$ & Yes vs no & 0.95 & 0.85 to 1.07 \\
\hline Pulmonary rehabilitation in RCT§ & Home vs hospital & 1.25 & 0.63 to 2.48 \\
\hline \multicolumn{4}{|l|}{ Multivariable analyses $₫$} \\
\hline Influenza vaccination & Yes vs no & 4.82 & 1.71 to 13.54 \\
\hline Cardiac disease & Yes vs no & 3.05 & 1.26 to 7.39 \\
\hline Age & Each year & 0.96 & 0.92 to 1.00 \\
\hline Post-BD FEV 1 & Each \% predicted & 0.98 & 0.95 to 1.00 \\
\hline Random effects & & Estimate & $95 \% \mathrm{Cl}$ \\
\hline Subject & & 0.47 & -0.32 to 1.26 \\
\hline Study centre & & 0.51 & -0.33 to 1.35 \\
\hline
\end{tabular}

*Adherence to the action plan was defined as the initiation of both prednisone and antibiotics within 3 days of exacerbation onset. All other actions were defined as non-adherence.

tCardiac disease includes chronic heart failure, angina pectoris, myocardial infarction and arrhythmia.

$\neq$ Depressive symptoms were measured with the 15-item Geriatric Depression Scale (GDS). Sum scores (range 0-15) $\geq 6$ points are suggestive for depression.

§Canadian pulmonary rehabilitation trial (http://ClinicalTrials.gov identifier: NCT00169897).

TAfter backward elimination with removal of variables with $\mathrm{p}>0.05$.

Post-BD FEV 1 , post-bronchodilator forced expiratory volume in $1 \mathrm{~s}$.

severity. Although adherence to pulmonary medication has been associated with older age, ${ }^{25}$ the current study showed that adherence to an action plan was associated with younger age. It is possible that adherence to an action plan is higher in younger subjects because of an increased perception by patients of the exacerbation on daily health and activities. Also, patients who received an influenza vaccination were more likely to adhere to their action plan. This may reflect a more favourable patient's belief or a higher quality of communication between the patient and provider. Depression has been shown to inhibit COPD selfmanagement, ${ }^{26}$ but depressive symptoms were not associated with action plan use in our study. Exacerbation sequence was not associated with action plan adherence. Since many patients experienced only one exacerbation over the 1-year study period, it is not realistic to expect adoption of a new behaviour in all patients. Successful past experiences can enhance self-efficacy, which is a predictor of behavioural change. ${ }^{19}$ An observation period of $>1$ year would better match the time frame in which self-management support objectives can be attained. Furthermore, a longer time course in which behaviour change can happen might result in a more realistic time allowance for longterm outcomes such as hospitalisations.

This study has several limitations. First, it was embedded in a randomised clinical trial that was designed for a different purpose. The results should thus be interpreted with some caution. Second, the written action plan was part of an intervention that consisted of the self-management programme 'Living Well with COPD' and pulmonary rehabilitation. The selfmanagement programme has previously demonstrated a significant reduction in healthcare utilisation and an improvement in health status, ${ }^{20}$ even after a 2 -year follow-up period. ${ }^{21}$ The pulmonary rehabilitation programme-home-based as well as hospital-based-has recently been shown to improve COPDspecific quality of life. ${ }^{18}$ The current study therefore does not allow us to draw any conclusions about the effects of a streamlined written action plan, only the use of an action plan as part of a more comprehensive self-management programme. On the other hand, the action plan was the only part of the intervention programme that specifically focused on exacerbation self-management. Third, $25 \%$ of the exacerbations had to be excluded because of missing exacerbation start or end dates and missing information regarding the use of antibiotics or prednisone. Although the excluded exacerbations did not differ from those analysed, this has definitely decreased the power of the study. Fourth, we excluded exacerbations that occurred within 14 days of the previous one and this could have affected the results. ${ }^{27}$ However, only $3.6 \%$ of the exacerbations were excluded for this reason and including them in the analyses did not change the statistical or clinical significance. Finally, to maximise the power of our study we used data of all exacerbations, thereby increasing the risk of introducing bias by frequent exacerbators. By entering the sequence of exacerbations as a variable in our multivariable regression models, we minimised this risk.

\section{Implications for practice and future research}

The results of this study have significant implications for clinical practice. We have shown that a written action plan is associated with a reduction in exacerbation total recovery time providing patients adhere to it. This suggests that action plans deserve a more prominent role in exacerbation management. However, less than half of the exacerbations were treated according to the instructions. Sufficient time and supportive coaching for patients should be allowed to improve the management of 
exacerbations. Although several factors were found that can be used by healthcare professionals to provide better self-management support, additional research on this topic is needed. Taking into account the negative results of previous studies, action plans should be carefully embedded in well-designed care delivery systems with easy access to care, including continuous reinforcement by case managers. This needs further research if we want a better understanding of what the specific components are, the time frame in which specific behaviour change such as using an action plan in the event of an exacerbation can be attained, and how best to support self-management in COPD. $^{28}$

Acknowledgements The authors acknowledge the contribution of Reinier Akkermans, statistician at the Scientific Institute for Quality of Health Care, Radboud University Nijmegen Medical Centre, The Netherlands who advised and supported the statistical analyses. The authors are grateful to all study personnel of each participating centre and to all participating patients for their dedication to this study.

Funding This study was sponsored by the Canadian Institutes of Health Research (MCT-63162) and by the Respiratory Health Network of the Fonds de la Recherche en Santé du Québec. EWMAB is the recipient of a MD-clinical research trainee stipend of The Netherlands Organization for Health Research and Development (ZonMw).

Competing interests None.

Patient consent Obtained.

Ethics approval This study was approved by the institutional research ethics board of each participating hospital and all subjects provided informed consent.

Contributors EWMAB, DHH, $A B, M S, S B, F M$ and JB participated in the original design of the study. SB, FM and JB supervised the collection of data. EWMAB, DHH and $A B$ performed the statistical analyses. EWMAB led the writing of the report, which was co-led by JB and MS and assisted by all other authors. All authors assisted in the interpretation of the study data and have seen and approved the final version of the report.

Provenance and peer review Not commissioned; externally peer reviewed.

\section{REFERENCES}

1. Seemungal TA, Donaldson GC, Paul EA, et al. Effect of exacerbation on quality of life in patients with chronic obstructive pulmonary disease. Am J Respir Crit Care Med 1998;157:1418-22.

2. Seemungal TA, Donaldson GC, Bhowmik A, et al. Time course and recovery of exacerbations in patients with chronic obstructive pulmonary disease. Am J Respir Crit Care Med 2000;161:1608-13

3. Miravitlles M, Ferrer M, Pont A, et al. Effect of exacerbations on quality of life in patients with chronic obstructive pulmonary disease: a 2 year follow up study. Thorax 2004;59:387-95

4. Bourbeau J, Ford G, Zackon $\mathrm{H}$, et al. Impact on patients' health status following early identification of a COPD exacerbation. Eur Respir J 2007;30:1-7.

5. Rabe KF, Hurd S, Anzueto A, et al. Global strategy for the diagnosis, management, and prevention of chronic obstructive pulmonary disease: GOLD executive summary. Am J Respir Crit Care Med 2007;176:532-55.
6. Kessler R, Stahl E, Vogelmeier C, et al. Patient understanding, detection, and experience of COPD exacerbations: an observational, interview-based study. Chest 2006;130:133-42.

7. Langsetmo L, Platt RW, Ernst $\mathrm{P}$, et al. Under-reporting exacerbations of COPD in longitudinal cohort. Am J Respir Crit Care Med 2008;177:396-401.

8. Wilkinson TM, Donaldson GC, Hurst JR, et al. Early therapy improves outcomes of exacerbations of chronic obstructive pulmonary disease. Am J Respir Crit Care Med 2004;169:1298-303.

9. Celli BR, MacNee W. Standards for the diagnosis and treatment of patients with COPD: a summary of the ATS/ERS position paper. Eur Respir J 2004;23:932-46.

10. Effing T, Monninkhof EM, Van der Valk PD, et al. Self-management education for patients with chronic obstructive pulmonary disease. Cochrane Database Syst Rev 2007; (4):CD002990

11. Taylor SJ, Candy B, Bryar RM, et al. Effectiveness of innovations in nurse led chronic disease management for patients with chronic obstructive pulmonary disease: systematic review of evidence. BMJ 2005;331:485.

12. Wood-Baker R, McGlone S, Venn A, et al. Written action plans in chronic obstructive pulmonary disease increase appropriate treatment for acute exacerbations. Respirology 2006;11:619-26.

13. McGeoch GR, Willsman KJ, Dowson CA, et al. Self-management plans in the primary care of patients with chronic obstructive pulmonary disease. Respirology 2006;11:611-18

14. Miravitlles M, Anzueto A, Legnani D, et al. Patient's perception of exacerbations of COPD: the PERCEIVE study. Respir Med 2007;101:453-60.

15. Nici L, Donner C, Wouters E, et al. American Thoracic Society/European Respiratory Society statement on pulmonary rehabilitation. Am J Respir Crit Care Med 2006;173:1390-413.

16. Turnock AC, Walter EH, Walters JA, et al. Action plans for chronic obstructive pulmonary disease. Cochrane Database Syst Rev 2005;(4):CD005074.

17. Maltais F, Bourbeau J, Lacasse $Y$, et al. A Canadian, multicentre, randomized clinical trial of home-based pulmonary rehabilitation in chronic obstructive pulmonary disease: rationale and method. Can Respir J 2005;12:193-8.

18. Maltais F, Bourbeau J, Shapiro S, et al. Effects of home-based pulmonary rehabilitation in patients with chronic obstructive pulmonary disease. Ann Intern Med 2008;149:869-78.

19. Bourbeau J, Nault D. Self-management strategies in chronic obstructive pulmonary disease. Clin Chest Med 2007;28:617-28.

20. Bourbeau J, Julien M, Maltais F, et al. Reduction of hospital utilization in patient with chronic obstructive pulmonary disease: a disease-specific self-management intervention. Arch Intern Med 2003;163:585-91.

21. Gadoury M-A, Schwartzman K, Rouleau M, et al. Self-management reduces both short- and long-term hospitalisation in COPD. Eur Respir J 2005;26:853-7.

22. Anthonisen NR, Manfreda J, Warren CPW, et al. Antibiotic therapy in exacerbations of chronic obstructive pulmonary disease. Ann Intern Med 1987;106:196-204.

23. Sedeno MF, Nault D, Hamd DH, et al. A self-management education program including an action plan for acute COPD exacerbations. COPD 2009;6:352-8.

24. Sridhar M, Taylor R, Dawson S, et al. A nurse-led intermediate care package in patients who have been hospitalised with an acute exacerbation of chronic obstructive pulmonary disease. Thorax 2008;63:194-200.

25. Rand CS, Nides M, Cowles MK, et al. Long-term metered-dose inhaler adherence in a clinical trial. The Lung Health Study Research Group. Am J Respir Crit Care Med 1995;152:580-8.

26. Dowson CA, Town Gl, Frampton C, et al. Psychopathology and illness beliefs influence COPD self-management. J Psychosom Res 2004;56:333-40.

27. Hurst JR, Donaldson GC, Quint JK, et al. Temporal clustering of exacerbations in chronic obstructive pulmonary disease. Am J Respir Crit Care Med 2009; 179:369-74.

28. Bourbeau J, van der Palen J. Promoting effective self-management programmes to improve COPD. Eur Respir J 2009;33:461-3. 